\title{
In-situ Sr isotope measurements for apatite: achieving precise data with high volume resolution using HR- SIMS
}

\author{
HEEJIN JEON AND MARTIN WHITEHOUSE
}

Swedish Museum of Natural History

Presenting Author: heejin.jeon@nrm.se

Apatite provides a powerful means to determine $\mathrm{Sr}$ isotopic composition $\left({ }^{87} \mathrm{Sr} /{ }^{86} \mathrm{Sr}\right)$ of ancient crust as it contains enough $\mathrm{Sr}$ to be measured but typically little $\mathrm{Rb}$. A number of studies to measure apatite $\mathrm{Sr}$ isotopes have been published using LA-ICPMS, but a little using SIMS [1,2]. Although utilising LG-SIMS is beneficial for small-volume targets, e.g., inclusions, it is technically challenging to measure $\mathrm{Sr}$ isotopes in apatite with good accuracy and precision by SIMS, mainly due to molecular interference (e.g., $\mathrm{Ca}$ dimers) on $\mathrm{Sr}$ isotopes that have not previously been thoroughly assessed. Here we present the method developed and results obtained using a CAMECA IMS1280 instrument.

Instead of separating $\mathrm{Ca}$ dimers from $\mathrm{Sr}$ isotopes using exceedingly-high mass resolution $(\Delta \mathrm{m} / \mathrm{m}>18 \mathrm{k})$, intermediate mass resolution (ca. 4500) was chosen to measure the combined signals of $\mathrm{Sr}$ isotopes and $\mathrm{Ca}_{2}$ [1,2]. After evaluating theoretically possible interferences affecting $\mathrm{Sr}$ isotope analysis of apatite by SIMS, all mesaureable and/or estimatable interferences (mainly $\mathrm{Ca}_{2}$ and $\mathrm{CaPO}$ tail) were corrected. Precise instrument tuning and mass calibration is essential to measure properly the combined signal and to minimise any interference contribution to $\mathrm{Sr}$ isotope measurement, as a few excess counts are critical to the accuracy of the $\mathrm{Sr}$ isotope ratio, particularly in low-Sr apatite. Empirical corrections were also required for the inadequate ${ }^{40} \mathrm{Ca}^{42} \mathrm{Ca}$-based $\mathrm{Ca}_{2}$ correction and for a slightly positive offset (ca. +0.0007 ) of unknown origin in ${ }^{87} \mathrm{Sr} /{ }^{86} \mathrm{Sr}$, and possibly for the contributions of some molecular interferences that cannot be resolved (for the apatite having high trace elements). The final corrected ${ }^{87} \mathrm{Sr} /{ }^{86} \mathrm{Sr}$ of the reference materials show good accuracy and precision with $1 \mathrm{SE}$ from ca. 0.0010 to 0.0002 obtained for $\mathrm{Sr}$ contents from $<100$ to $1500 \mathrm{ppm}$ [3].

[1] A. Lepland \& M. J. Whitehouse (2011), Int J Earth Sci $100,1-22$.

[2] J. Gillespie et al. (2021), Chem. Geol, 559, 119979.

[3] H. Jeon \& M. J. Whitehouse (2021), Geostand Geoanal Res, doi:10.1111/ggr.12377 